\title{
Is myocardial performance index useful in differential diagnosis of moderate and severe hypoxic-ischaemic encephalopathy? A serial Doppler echocardiographic evaluation - CORRIGENDUM
}

\author{
Sevim Karaarslan, Hayrullah Alp, Tamer Baysal, Derya Çimen, Rahmi Örs, Bülent Oran
}

doi:10.1017/S104795111200011X, Published by Cambridge University Press, 13 February 2012.

First published online: 8 March 2012

The authors apologise for an error in the Corresponding author's affiliation details given in the footnote on page 1 of the article. It incorrectly states Selcuk University as the affiliation; however this should be Konya University, due to a recent name change. Therefore the full details for the Corresponding author should read as follows:

Correspondence to: Dr H. Alp, Department of Pediatric Cardiology, Meram Medical Faculty, Konya
University, Konya, Turkey. Tel: 190332223 6429; Fax: 190332223 6585; E-mail: drhayrullahalp@ hotmail.com

\section{Reference}

Karaarslan S, Alp H, Baysal T, Çimen D, Örs R, Oran B. Is myocardial performance index useful in differential diagnosis of moderate and severe hypoxic-ischaemic encephalopathy? A serial Doppler echocardiographic evaluation. Published by Cambridge University Press, 13 February 2012. doi:10.1017/S104795111200011X. 